\title{
Coalition formation on major policy dimensions: The Council of the European Union 1998 to 2004
}

\author{
Peter van Roozendaal • Madeleine O. Hosli • \\ Caspar Heetman
}

Received: 8 April 2009 / Accepted: 13 May 2011 / Published online: 13 July 2011

(C) The Author(s) 2011. This article is published with open access at Springerlink.com

\begin{abstract}
Using data of contested decisions in the Council of the European Union, combined with data on the position of member states on the left-right and support for European integration dimensions, this paper provides an overview of winning coalitions formed in the council in the 1998 to 2004 time span. It shows distance between the combined policy positions of winning coalitions to individual EU states within these coalitions and demonstrates that most winning coalitions in the Council have a large combined voting weight, minimal winning coalitions are rare, and ideological connectedness plays a much smaller role than expected.
\end{abstract}

Keywords Council of the EU · Coalition-formation · Qualified majority voting · Policy dimensions $\cdot$ EU political space $\cdot$ Contested decisions

\section{Introduction}

In the last decades, much work has examined the power of different actors in the European Union (EU) in the context of the EU's legislative procedures (e.g., Crombez 1996; Steunenberg 1994; Steunenberg et al. 1999; Garrett and Tsebelis 2001). Other studies have

P. van Roozendaal

Netherlands Court of Audit, The Hague, The Netherlands

e-mail: P.vanRoozendaal@ rekenkamer.nl

P. van Roozendaal

Leiden University, Leiden, The Netherlands

M.O. Hosli (凶)

Department of Political Science, Leiden University, P.O. Box 9555, 2300 RB Leiden, The Netherlands e-mail: hosli@fsw.leidenuniv.nl

C. Heetman

University of Antwerpen, Edegem, Belgium

e-mail: Caspar.Heetman@gmail.com 
focused on the voting power of EU states in the Council of the EU, notably in the context of an expanding Union (e.g., Widgrén 1994; Hosli 1996; Nurmi and Meskanen 1999; Hosli and Machover 2004). By comparison, only little academic research has been devoted to the analysis of the actual voting behavior of EU states in the Council. Presumably, the main reason for this dearth of analysis is that decision-making in the Council generally takes place behind closed doors.

A number of recent analyses, however, do provide insights into the actual voting behavior of EU states in the Council (e.g., Mattila and Lane 2001; Mattila 2004; Heisenberg 2005; Hagemann 2005; Hayes-Renshaw et al. 2006; Hosli 2007; Hagemann and Hoyland 2008; Plechanovová 2011; Hosli et al. 2011). These studies analyze the voting behavior of individual member states, distinguishing between the basic vote choices for EU states (i.e., support, reject or abstain). Among these works, there is some variation in research design, the operationalization of dependent and independent variables, and estimates of the effects of a range of independent variables on voting behavior in the Council. For example, whereas Hayes-Renshaw et al. (2006) find that governments' left-right policy division does not systematically influence voting behavior in the Council, Mattila (2004) discovers a moderate effect of this variable on vote choice, and Hagemann's (2005) analysis shows that this variable has a strong and significant effect. Hosli (2007) claims that it is not absolute left-right positioning that matters, but the relative positioning of governments of EU states on this policy scale. This implies that governments more distant from the average EU left-right policy position are significantly more inclined to oppose decisions in the Council.

In this paper, we use a different approach to analyzing voting behavior in the Council. Each group of EU member states that either votes for or against a new policy proposed by the Commission is considered to constitute a coalition. For each decision, coalitions of member states form in which countries with similar policy priorities are likely to vote in the same way. The final result of each vote in the Council is either adoption or rejection of a policy proposal. If a proposal is supported, its proponents in the Council have formed a winning coalition. When it is rejected, one of two situations may apply: either a winning coalition has been formed against the policy proposal, or a blocking coalition has been established (i.e., a minority coalition which, due to the specific voting rule used, has a sufficient number of votes to prevent a legislative proposal from being adopted).

In recent decades, many models of coalition-formation have been developed, both from the perspective of cooperative and non-cooperative game theory. Several of these models are applied, for example, in the edited volume The European Union Decides (Thomson et al. 2006). Empirical applications of these models are found in work on government coalitionformation processes in multiparty democracies and often include predictions regarding their durability (e.g., Laver and Schofield 1990; Laver and Shepsle 1996; Grofman and Van Roozendaal 1996). An extensive overview of recent approaches is provided in Schofield (2008).

These models have in common that each coalition-formation process or voting procedure is seen as an independent event. In decision-making in the EU Council, ${ }^{1}$ this is not always the case, but extending existing models to address this limitation exceeds the scope of the present study. Instead, we assume that votes are cast independently, providing a baseline scenario for assessing coalition-formation in the Council.

\footnotetext{
${ }^{1}$ We will use the term 'EU Council' throughout this article. This institution is the Council of the European Union (earlier the 'Council of Ministers') and should not be confused with the European Council, which is composed by the Heads of State and Government of the EU member states.
} 
In the subsequent analysis, we focus on the final decisions made in one of the Council configurations. ${ }^{2}$ More often than not in Council voting processes, the winning coalition is a grand coalition encompassing all EU states, since the differences of opinion between the states are resolved in the preceding stages of the Council working groups and the meetings of the Committee of Permanent Representatives (COREPER) of each member state. This is due to the informal norm of consensus prevalent in EU decision-making (e.g., Mattila and Lane 2001; Hix 1999a, 1999b; Sherrington 2000; Heisenberg 2005). Although in many instances it is not formally necessary, in practice, negotiations between EU states often continue until consensus is reached.

In this dynamic negotiation process, EU member states can either retain their original position or shift their preference to a different position. This can be explained by a variety of factors: new information can lead to position shifts and political pressures or self-interest may induce logrolling or vote trading (Tullock 1976; Bueno de Mesquita and Stokman 1994). Some of the most controversial proposals, however, may remain contentious until the end of the negotiation process. Alternatively, certain countries may wish to 'make a point' or a 'statement' in the Council's decision-making process, usually in an effort to appease their domestic political audience. In these cases, the final decision has to be taken in the EU, and different types of winning coalitions consisting of different constellations of EU states may form. This is the topic we explore in the current paper. We also aim to contribute to the discussion of whether analyses of EU decision-making can be based on one-dimensional conceptualizations, or whether more dimensions should be considered.

Our paper is structured as follows. The next section describes aspects of the voting process in the EU Council. Section 3 presents a selection of classical models of coalitionformation that may be particularly relevant to processes of Council decision-making. Section 4 introduces the data that will be used in this paper. Section 5 presents the results of our empirical analysis and finally, Section 6 summarizes the main findings of our analysis and concludes the paper.

\section{Characteristics of the Council voting process}

The main actors involved in the preparation of new EU policy proposals are the European Commission, the EU Council and the European Parliament (EP). According to the current legislative provisions, the formal right of initiative for policy proposals lies with the European Commission. The Council, the EP and member states may make suggestions to the Commission and can call on the Commission to present new proposals, but it is the European Commission that actually drafts proposals.

Generally, several steps are taken before the Commission presents a proposal to the EU's member states. Specialists from the member states' ministries participate in several working groups, expert bodies or informal meetings during the initial stages of the decision-making process. Once the exploratory stage has ended and the Commission has published its new policy proposal, two processes occur simultaneously: (a) the policy proposal is sent to all EU member states and (b) negotiations between the member states start in Brussels.

\footnotetext{
${ }^{2}$ Currently, there are nine different configurations of the Council: (1) General affairs and external relations, (2) Economic and financial affairs, (3) Cooperation for Justice and Home affairs, (4) Employment, social policy, health and consumer affairs, (5) Competitiveness, (6) Transport, telecommunications and energy, (7) Agriculture and fisheries, (8) Environment and (9) Education, youth and culture.
} 
Strengthening the EU's democratic foundations, each government can provide its domestic parliament with information on the proposed new EU policy, and use this information in the negotiation process. The negotiations are first conducted in a Council working group where most of the logrolling occurs. This is the most time-consuming phase of the decision making process. Regardless of whether or not an agreement is reached in the Council working group, subsequently the COREPER - the Committee of Permanent Representatives to the EU-discusses the subject. The final decision, however, is made in the relevant configuration of the Council of the EU, and depending on whether or not co-decision is applicable as a legislative procedure, the proposal may also need to be formally dealt with by the EP. Since the ratification of the Treaty of Lisbon, co-decision constitutes the standard EU legislative procedure.

At the end of this extended process of preparation, formal voting in the Council may take place. In fact, many policy proposals are never voted on formally, as the participants in the respective Council meetings (especially the presidency) know whether the required majority among EU member states has been reached in support of a proposal. Depending on the type of initiative at hand, a simple majority, a qualified majority or unanimity is required for formal Council decision-making. In most cases, the Council can decide on the basis of a qualified majority vote (QMV). The simple majority voting rule applies for a smaller number of decisions, such as internal Council rules and the organization of the Council secretariat. Unanimity is required for only a small number of decisions. However, these include some politically salient issues, such as social and tax harmonization.

In general, the Council strives to achieve consensus in order to avoid needing to resort to a formal vote. It tends to seek unanimity even when this is not formally required. ${ }^{3}$ The most commonly used decision procedure in the Council is QMV. Between January 1995 and November 2004 - the month the Nice Treaty provisions became effective-QMV required that 62 out of 87 total votes $(71.3 \%)$ be cast in favor of a proposal. ${ }^{4}$ However, if members of the Council who together represented 23 to 25 votes stated their intention to oppose the adoption of a decision based on QMV, the Council had to search for a solution (e.g., a modified version of the suggested legislative provision) sufficiently acceptable to garner at least 65 votes in favor. ${ }^{5}$ Otherwise, the decision failed to be adopted.

This paper will focus on the years 1998 through 2004, a stable phase of the European Union, as it did not enlarge beyond its then 15 member states. In this time span, the total number of votes in the Council was 87: France, Germany, Italy and the United Kingdom each had ten votes, Spain had eight, The Netherlands, Belgium, Greece and Portugal had five votes, Austria and Sweden four, Denmark, Ireland and Finland had three votes, and Luxemburg had two.

\footnotetext{
${ }^{3}$ This motive dates back to the 'Luxembourg compromise' in 1966, which ended a dispute between France and the other European Community member states. In 1965, France refused to cede unanimity in favor of QMV as was required for certain decisions by the Treaty of Rome; subsequently, France refused to take its seat in the Council for six months.

${ }^{4}$ In the event of a decision without a Commission proposal, in the 1995 to 2004 constellation of EU membership, the 62 votes in favor had to be cast by at least ten member states.

${ }^{5}$ For the expansion in 1995, which brought Austria, Finland and Sweden into the EU, the United Kingdom asked for a decision threshold of more than 62 votes. This led to a compromise that was agreed upon at the European Council of March 1994 in Ioannina, Greece: if members of the Council who together represented 23 to 25 votes stated their intention of opposing the adoption of a decision by qualified majority, the Council would do everything in its power to obtain a satisfactory solution. This solution had to be adopted by at least 65 votes within a reasonable period of time and without prejudice to the mandatory time limits specified by the treaties and secondary legislation.
} 
In 2004, the EU was enlarged with the addition of ten new states: the most significant expansion of the EU's membership in history. In 2007, two more states were added to the European Union: Bulgaria and Romania. In light of the addition of new states, the decision rules regarding distribution of votes in the Council constituted a major issue in the negotiations leading to the Nice Treaty, as well as in the later discussions on the European Constitutional Treaty and the Lisbon Treaty. The Lisbon Treaty adopted the provisions that had been agreed upon earlier by the European Council (in a summit meeting leading to an adaptation of the provisions foreseen by the Convention on the Future of Europe, which had met in 2002 and 2003).

Until the provisions of the Lisbon Treaty take effect in 2014, notably the introduction of a new double-majority scheme-in which Council decisions will require a majority of $65 \%$ of EU population as represented in the Council, as well a majority of 55 percent of EU member states - the decision rules incorporated into the Treaty of Nice will apply. ${ }^{6}$ This treaty implemented a triple-majority clause for Council decision-making, implying that a decision in the Council needs to be accepted by a qualified majority of a minimum of 255 votes out of the total of 345 votes (approximately 74\%), a majority of $62 \%$ of the EU population as represented in the Council, and a majority (more than 50\%) of member states. Felsenthal and Machover (2001) have demonstrated, however, that the last provision is redundant as there is no winning coalition in the Council that meets the first two criteria but fails to meet the third one.

In the following analysis, we will use Council voting data for the years 1998 to 2004 . Since the new provisions of the Nice Treaty only became effective in 2004, our analysis will be limited to a phase in which both EU membership and Council voting rules remained constant, but voting records and data for our independent variables are available in a systematic way.

\section{Models of coalition-formation}

In the last decades, several models of coalition-formation have been developed on the basis of both cooperative and non-cooperative game theory. ${ }^{7}$ Decision-making in the EU's Council evidently has non-cooperative features, and corresponding models have become highly popular in academic research focusing on the EU. However, the day-to-day reality of decision-making in Brussels does contain cooperative aspects which warrant further study. In this article, we focus on such cooperative features of the EU decision-making process, by assessing a number of classical coalition models developed on the basis of cooperative game theory.

We suggest that decision-making in the EU's Council-like government coalitionformation in multiparty democracies - may essentially be modeled as a weighted majority game: a special variant of simple games (Shapley 1962; Shapley and Shubik 1954; Rapoport 1970) within the category of cooperative $n$-person games (Luce and Raiffa 1957; Riker and Ordeshook 1973). These games are described extensively, for example, in van

\footnotetext{
${ }^{6}$ In practice, member states can demand a confirmation that votes in favor of a proposal in the Council represent at least $62 \%$ of the total EU population.

${ }^{7}$ For the latter category, see, for example, Austen-Smith and Banks (1988), Baron and Diermeier (2001) and Sened (1995). For an extensive overview of different approaches to the analysis of politics, see Schofield (2008).
} 
Deemen $(1989,1997)$. For this reason, we provide only an informal description of some of the elements that are most relevant to our approach.

In a weighted majority game, each player $i$ has a certain weight $w_{i}$, representing the voting or decision-making powers of the participants. The total weight in the game is the sum of the weights of the participating players. In a weighted majority game, a coalition is winning if the sum of the weights of its members is at least equal to a certain prescribed majority criterion, also termed the 'quota' of the game (subsequently denoted by $q$ ). The value of $q$ may differ between areas of potential application. For example, in parliamentary coalition-formation in multiparty democracies where a simple majority counts, $q$ is half the total weight of the game plus 1. Alternatively, in the EU's Council, with fifteen member states, for the time span analyzed in this paper and for QMV, the value of $q$ is $62 / 87$. Consequently, for a coalition in the Council to win a vote on a given policy proposal, at least 62 of 87 votes are required. Alternatively, a minority coalition can block the adoption of a certain policy in the Council if the combined weight of the players within that coalition is at least 26 votes. The weighted majority game of voting in the Council in this phase $(G)$-can be represented as follows:

$$
G=[62 ; 10,10,10,10,8,5,5,5,5,4,4,3,3,3,2]
$$

In $G, 62$ is the decision threshold in the EU Council—applicable in the 1998 to 2004 time span-and the weights of the players in $G$ are the voting weights of member states. A player $i$ is a veto player if it is a member of every winning coalition, as this player can turn any winning coalition into a losing one by leaving it. If a veto player exists, this actor is necessary for any coalition to win. In the case of QMV in the EU's Council, there are no veto players; by comparison, when the unanimity provision applies, every EU state constitutes a veto player.

Different approaches developed in the framework of cooperative game-theoretic models can roughly be divided into two groups: the 'size only' models on the one hand, and the 'policy oriented' models on the other. The latter category can be sub-divided into models using a one-dimensional policy space and those based on a multi-dimensional space.

As far as the 'size only' models are concerned, Von Neumann and Morgenstern (1947) termed a winning coalition a 'minimal winning coalition' if every subset of this entity is a losing coalition. In the case of QMV in the EU Council, these minimal winning coalitions are winning coalitions whose combined weight drops below 62 when any of the member states leaves it. Special sets of minimal winning coalitions are 'minimum size coalitions': according to Riker (1962), only minimal winning coalitions of the smallest size are likely to form. ${ }^{8}$ This implies that in parliamentary settings, for example, governments will most likely be composed of coalitions that are (a) minimal winning and (b) smallest in size as measured by the total number of parliamentary seats the coalition encompasses. In efforts to predict coalition-formation, this principle helps reducing the number of potential minimal winning coalitions. In the EU Council, a minimum size coalition is the smallest among all winning coalitions whose combined weight drops below 62 if any of the member states defects.

In contrast, the 'policy oriented' models utilize the concept of minimal connected winning coalitions as introduced by Axelrod (1970). Connectedness in one-dimensional policy space is also an important feature in De Swaan's (1973) policy distance theory. Coalitions in Axelrod's conceptualization must be winning, consist of players adjacent to one another on the respective policy scale, and be minimal in the sense that the coalition cannot lose

\footnotetext{
${ }^{8}$ For a thorough discussion, analysis and extension of Riker's model, see Schofield (2008).
} 
any players without ceasing to be either connected or winning. In comparison, De Swaan's approach selects among these coalitions by predicting that coalitions with the smallest range between the two most extreme players on the respective policy scale will form. A prominent element of De Swaan's coalition-formation theory is the pivotal player. This player represents the median weighted position of all actors, ordered on an underlying policy dimension. The median weighted position is considered the most probable expected combined policy position for the coalition as a whole and, accordingly, a player will prefer coalitions in which it is pivotal. Among the coalitions in which it is pivotal, the player prefers the coalition with the smallest absolute excess, i.e., the coalition with the smallest absolute difference between the weight of players located to its left and right.

In government coalition-formation processes, the pivotal player is known as the central player (Van Deemen 1987; Van Roozendaal 1992a, 1992b). Let $R$ denote an ordering of the placement of parties on a given dimension. ${ }^{9}$ In a simple game, central player $i$ on policy order $R$ can be identified as follows: $R+(i)$ is the coalition of all players whose policy positions are located to the left of $i$ on policy order $R . R-(i)$ is the coalition of all players whose policy positions are located to the right of $i$ on policy order $R$. Player $i$ is the central player of a government coalition formation game (where $q$ is always half the total weight of the game plus 1 ) when the absolute value of the weight of $R+(i)$, minus the weight of $R-(i)$, is smaller than the weight of $i$.

A central player is powerful in government coalition formation games because of its policy position. The (connected) coalition of all players to the left of $i$ on $R$ can win only if $i$ joins this coalition; the same holds for the (connected) coalition of all players to the right of $i$ on $R .^{10}$

The intuitively attractive central player model can be used to examine coalition formation in the Council under simple majority voting. However, it is not applicable to QMV, because when the relative value of $q$ increases beyond one-half plus one, it is no longer necessarily possible to have one central player. Consider the earlier weighted majority $G$ and assume that the players are ordered from left to right. ${ }^{11}$ To find the central player on that scale, we display a game $G$ in which the weights of the players-starting from either the left-hand or the right-hand side of the policy scale and adjacent to one another-sum up to required decision threshold. From left to right, this would be

$$
G=[62 ; \mathbf{1 0}, \mathbf{1 0}, \mathbf{1 0}, \mathbf{1 0}, \mathbf{8}, \mathbf{5}, \mathbf{5}, \mathbf{5}, 5,4,4,3,3,3,2]
$$

And from right to left, we find:

$$
G=[62 ; 10,10, \mathbf{1 0}, \mathbf{1 0}, \mathbf{8}, \mathbf{5}, \mathbf{5}, \mathbf{5}, \mathbf{5}, \mathbf{4}, \mathbf{4}, \mathbf{3}, \mathbf{3}, \mathbf{3}, \mathbf{2}]
$$

\footnotetext{
${ }^{9}$ Policy order $R$ satisfies the following properties: it is reflexive (for any player $i \in N: i R i$ ), complete (for any two players $i, j \in N$ either $i R j$ or $j R i$ ) and transitive (for any three players $i, j, k \in N$ : if $i R j$ and $j R k$, then $i R k)$.

${ }^{10}$ Schofield's (2008) analysis of multiparty systems examines whether a political party can occupy a structurally stable core position. In a one-dimensional model, a core party always exists, because there always is a party to which the median legislator belongs (see Schofield 2008: 130). However, there is some contestation in the literature, also as regards American politics, whether the issue space can be reduced to a single left-right dimension (and if so, for which time periods).

${ }^{11}$ In this specific example, for presentational purposes, the players are ordered from left to right according to their voting weights. However, a centrality area also exists for every other ordering of the players.
} 
Instead of a central player, we propose that under QMV the Council includes the centrality area for each relevant policy dimension. In this example, in which players are ordered by weights, the centrality area is determined by the players included in the QMV winning coalition when either starting to the left or the right of the scale:

$$
\begin{gathered}
G=[62 ; 10,10, \mathbf{1 0}, \mathbf{1 0}, \mathbf{8}, \mathbf{5}, \mathbf{5}, \mathbf{5}, 5,4,4,3,3,3,2] \\
\uparrow-----\uparrow
\end{gathered}
$$

This implies that no (connected) winning coalition can form under QMV without inclusion of the players located in the centrality area.

Aiming to assess the effects of coalition-formation and voting in the EU's Council, Hosli and Van Deemen (2002) discuss the potential effects of enlargement on the efficiency of decision-making, using cooperative game theory. ${ }^{12}$ The second part of their analysis assumes that EU states align according to an underlying one-dimensional policy scale and that only connected coalitions among EU states will form. By comparison, in the multidimensional elaborations of Axelrod's (1970) conflict of interest theory, aiming to predict decision outcomes in the EU's Council, Boekhoorn et al. (2006) apply two models that minimize conflict among the coalition partners in the EU decision-making process. These models can be interpreted as 'consensus maximization models,' and predict that coalitions forming in the Council will have minimal conflict. When tested against empirical data on EU decision-making, the models generate fairly accurate predictions.

In research on the European Parliament, analyzing roll call votes, Hix et al. (2007) apply models based on policy dimensions to voting within this institution. The main finding of their analysis is that the policy preferences of the parties represented in the EP are more important than size-related factors in determining the coalitions formed in practice. I.e., the 'policy oriented' models do a better job of predicting coalition patterns than do the 'size only' models. In addition, their analysis demonstrates that the left-right scale is the most important policy dimension for determining political conflict and voting (for similar results with respect to the Council, see Hagemann 2005; Hagemann and Hoyland 2008).

By comparison, on the basis of an analysis of European parliamentary party manifestos, Hix (1999b) finds that two major policy dimensions structure behavior in the European Union: an integration-independence and a left-right policy dimension. His study partially corroborates earlier insights provided by Hix and Lord (1997). For the following empirical analysis, we will, in correspondence with earlier research, assume that both the left-right and the support for European integration dimension matter to political conflict in the European Union.

Clearly, in the analysis of multiparty systems, different dimensions may be salient. For example, the final chapter in Schofield (2008) demonstrates that in U.S. politics, both an economic and a social axis matter. ${ }^{13}$ In the following analysis, we aim to get a first glimpse of the types of winning coalitions formed and the dimensionality of the political space in the EU's Council when the issues at stake were contested among its member states. Given that

\footnotetext{
${ }^{12}$ On efficiency and fairness related to different QMV rules—and thresholds—-for the EU's Council, see Leech (2002). On bargaining, enlargement and differential or discriminatory membership in the EU, see Schneider (2007).

${ }^{13}$ This is also clearly expressed in the following statement: "There is substantial evidence that it is necessary to employ a two-dimensional policy model with both economic and social axes in oder to understand American politics" (Schofield 2008: 253).
} 
in such situations the Council does not aim to reach consensus, it is interesting to explore the rules that govern decision-making in these more controversial cases.

As the Council is one of the EU's preeminent decision-making bodies, our first expectation is that notable theories of coalition-formation accounting for policy orientations will be most applicable. Accordingly, in our analysis, we evaluate one-dimensional approaches to coalition-formation, using first the left-right policy scale as the most likely dimension of political conflict in the EU (e.g., Hix 1999b; Gabel and Hix 2002; Aspinwall 2002; Hix et al. 2007), and, secondly, the support for EU integration dimension (e.g., Mattila 2004; Hosli 2007). We make our first expectation more specific by examining for these two dimensions - in ascending order of complexity - whether the winning coalitions formed in the Council (a) contain the centrality area, (b) are connected winning, and (c) are minimal connected winning. ${ }^{14}$ Finally, we will simultaneously examine whether the winning coalitions are also (d) minimal winning.

In his Policy Distance Theory, De Swaan (1973) predicted that a player will prefer a winning coalition whose combined policy position is as close as possible to its own preferred policy. There is no reason to assume that EU states in the Council, having abandoned the voluntary aim to reach consensus, do not act on the basis of similar rational preferences. Accordingly, if consensus cannot be achieved, it is likely that an EU member state will prefer an outcome close to its own policy position as compared to one distant from its own priorities. Hence, a second expectation to be tested in this article is that member states will vote more often than not in favor of a proposal when the policy distance between their own position and the combined position of the winning coalition in the Council is small. To evaluate this expectation, we examine (a) the combined weighted policy position of each winning coalition in the Council on both dimensions examined and (b) the relation of this combined policy position to the policy positions of the member states encompassed in these coalitions, for both policy issues. ${ }^{15}$ Using this approach, we can identify the member states with significant or insignificant congruence of their own policy positions and the ones of the coalitions in which they participate. In a somewhat oversimplified approach, states with high or low congruence can be labeled 'winners' or 'losers' in the negotiation process, respectively.

\section{Data on Council decision-making and alignment on policy scales}

To test empirically the kinds of coalitions that have formed in the Council and to see how much individual EU states have given in to achieve a final winning coalition, we use two data sources. The first dataset has been described extensively by Hayes-Renshaw et al. (2006). ${ }^{16}$

\footnotetext{
${ }^{14}$ In future research we also aim to explore whether the winning coalitions have a combined minimal policy distance (e). Note, however, that whereas (a)-(c) simply require an ordinal ranking of the member states along the relevant policy dimension (see also Van Roozendaal 1994), policy distance theory requires an intervallevel ordering. If, for the latter, ordinal positions are considered, the results will coincide with (c). It has to be kept in mind, however, that for multi-party systems, even experts may end up with different arguments with respect to the ordering of political parties. Accordingly, assessing intervals between actor policy positions is complicated empirically.

${ }^{15}$ For this assessment, we use information on the location of political actors on interval scales. Experts may indeed attribute different positions to political parties on respective single-dimensional scales; we are aware of this complication, but will clearly provide the sources that lead to our assessments on the two dimensions of political contestation accounted for in this paper.

${ }^{16}$ The accompanying data are available electronically on www.councildata.cergu.gu.se/Council\%20Data/ Wallace/Wallace.htm.
} 
It provides information, inter alia, on the EU states that abstained or cast negative votes in contested decisions between the years 1998 and 2004.

In addition to this, we use data provided by Hosli (2007) to locate EU states on underlying policy dimensions and to evaluate the coalitions formed in the Council. This data set specifies the location of governments on both the left-right and the support for EU integration dimension. To locate governments on the left-right policy scale and to account for the fact that coalition governments were composed of politicians representing different domestic political parties, the data were collected using the following procedure. For each year and each EU member state, government left-right location was assessed in terms of the number of cabinet posts held by representatives of state-specific political parties. This meant that as cabinets changed over time, the policy position of member states in the Council also moved.

In Hosli's (2007) data set, each government's left-right policy position was first assessed using information from Laver and Hunt (1992) and Benoit and Laver (2005). A second collection of data points specifying parties' left-right positions is based on data collected by Leonard Ray in 1984, 1988, 1992 and 1996 and by Marks and Steenbergen (2004). Leftright positions are determined by weighing the number of cabinet posts held by domestic political parties in both annual and biannual intervals for each EU member state government. Our analysis uses the yearly information from these data and resorts to the information provided by Marks and Steenbergen. Unfortunately, in this data collection, information specifying the left-right positioning for the government of Luxemburg is not available. However, government positioning at the left-right scale in the Marks and Steenbergen and the Benoit and Laver data sets are highly correlated. Accordingly, we feel confident in substituting the Benoit and Laver data for the missing Luxemburg entry of the Marks and Steenbergen data set.

In our analysis, left-right positions of member state governments are assigned values between a theoretical minimum of 0 (most leftist) and a maximum of 1 (most rightist). In practice, the most leftist position of a member state was 0.32 (the French government between 1998 and 2001). By comparison, the most rightist position was 0.78 (Austria in 2001 and 2002).

Hosli (2007) — building on the analysis by Mattila (2004) of possible alternative dimensions of EU political disagreement-examines the extent to which levels of public support for EU integration influence voting behavior of EU states in the Council. She finds that the more Euroskeptic an EU member state's citizens, the more likely its government is to vote against a policy proposal in the Council. ${ }^{17}$ Accordingly, the present study, focusing exclusively on that body's controversial decisions, will investigate the extent to which the location of an EU state on the support for EU integration dimension influences patterns of coalition formation. In our analysis, data capturing public support for European integration (as used in Mattila 2004 and Hosli 2007) is based on Eurobarometer data for the 1998 to 2004 time span. This information demonstrates the extent to which governments faced EU-friendly or Euroskeptic domestic audiences. ${ }^{18}$

Clearly, both data sources provide a somewhat rough indication of the position of member states on each of these policy dimensions and fail to give information on individual policy issues. Although inclusion of more detailed information would be preferable, it is

\footnotetext{
${ }^{17}$ For the post-2004 phase, however, the link between support for European integration and voting behavior in the Council seems to be partially reversed. See Hosli et al. (2011).

${ }^{18}$ The location of political actors on this dimension is likely to be less controversial than interval-level assessments on the left-right policy scale, as support for European integration in public opinion is based on (easily quantifiable) Eurobarometer surveys.
} 
Fig. 1 Number of times winning coalitions with a given grouped voting weight were formed in Council decision making, 1998-2004 $(N=391)$

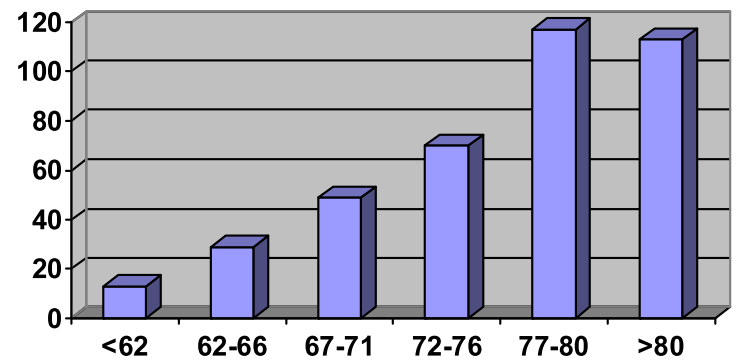

Number of times a winning coalition with a given grouped voting weight is formed

unfortunately not available for all countries on all issues. This implies that coalitions in our analysis cannot be assessed on an issue-by-issue basis, but that we provide a fairly aggregated picture of coalition-formation in the EU's Council.

Combining left-right and support for EU integration data with information on Council voting behavior allows assessing the types of winning coalitions formed in contested decisions in the EU's Council between 1998 and 2004. The combined data set consists of a total of 466 cases. After removing cases that failed to pass, and cases for which the voting rule was unclear, 391 cases remain for quantitative assessment. Of these 391 cases, 265 decisions were made under the QMV rule, 99 decisions required simple majority voting, and 27 decisions had to be taken unanimously. ${ }^{19}$

\section{Empirical results}

First, it seems important to assess the extent to which the left-right and support for European integration dimensions may be interrelated. Although intuitively, the dimensions are interdependent, no significant correlation can be found empirically. ${ }^{20}$ This finding is also in agreement with Hosli et al. (2011) for the post-2004 time span, in which these dimensions are uncorrelated. ${ }^{21}$ Accordingly, we will proceed by essentially assuming independence between these two dimensions of political contestation that have been found to matter in earlier empirical research on EU decision-making.

The first part of our empirical analysis assesses the types of winning coalitions formed in the Council for contested votes between 1998 and 2004. In the second part, the policy positions of these winning coalitions will be assessed based on information regarding the respective policy positions of member states within these coalitions.

\footnotetext{
${ }^{19}$ Note that even in the framework of the unanimity rule, the outcome of a decision may be controversial if one or more states abstain from voting.

${ }^{20}$ This also holds for the entire 1995 to 2004 time span - the EU 15-in which Pearson's correlation coefficient $(r)$ for these two dimensions is less than 0.2, using our assessments for the two policy scales.

${ }^{21}$ Other recent work on EU decision-making shows, however, that these two dimensions may be related in non-linear ways, as support for European integration appears to be linked to the left-right policy dimension in the form of an "inverted u-curve": actors at the extremes of the left-right policy scale seem to be less pro-integration than those in the center of the scale. On this issue, see, e.g., Hooghe et al. (2002), Aspinwall (2002), Hosli (2007).
} 
Table 1 Characteristics of winning coalitions in the Council of the EU under different voting rules (1998-2004)

${ }^{a}$ Officially for votes under unanimity the majority criterion is 87 . Because abstentions are possible, however, the criterion can have a lower value in practice

\begin{tabular}{llcc}
\hline & Simple majority & Qualified majority & Unanimity \\
\hline$N$ & 99 & 265 & 27 \\
Majority criterion & 44 & 62 & $87^{\mathrm{a}}$ \\
Mean weight & 73.85 & 75.69 & 78.30 \\
Standard deviation & 9.4 & 6.2 & 4.8 \\
Minimum weight & 49 & 62 & 62 \\
Maximum weight & 84 & 85 & 85 \\
Range in weight & 35 & 23 & 23 \\
\hline
\end{tabular}

In Fig. 1, the combined voting weight of the winning coalitions is classified into six groups, and plotted against the number of times a winning coalition in this category formed. Table 1 provides an overview of the general characteristics of the winning coalitions.

In situations in which no unanimous winning coalition was formed and the formal requirement to do so was lacking, there still was a trend to reach unanimity: 300 of the total of 391 winning coalitions have an aggregate weight between 72 and 85 votes, and 91 coalitions have a combined weight of between 50 and 72 votes. Given the well-known fact that a central feature of decision-making in the EU Council is the search for unanimity, it is surprising to see that in approximately $25 \%$ of all cases unanimity was not even close to being reached.

Surprisingly, Table 1 shows that the differences between the mean total weights of the winning coalitions under different voting rules are not that large, ranging from 73.9 for simple majority to 78.3 for unanimity. However, a one-way ANOVA test shows that the difference between the mean total weights of the coalitions, under different voting rules, is indeed statistically significant $(F=4.88, p<0.01)$. Finally, although under the simple majority requirement only 44 votes were needed to win, 86 of the 99 winning coalitions in this category would also have passed the QMV threshold.

Table 2 shows how many times each EU state joined a winning coalition (i.e., when it voted in favor of a proposal that was in fact adopted). A striking result is that 12 of the 15 EU states participated in winning coalitions at least $80 \%$ of the time. Moreover, of these 12 EU states, 10 voted for the proposed decision at least $87 \%$ of the time. Member states that participated in winning coalitions most frequently are, in decreasing order, Greece $(94,4 \%)$, Luxemburg (93,9\%), Ireland (93,9\%), and France (93,6\%). By comparison, member states that were part of winning coalitions least frequently are the Netherlands $(77,2 \%)$, Sweden $(72,9 \%)$ and Denmark $(68,5 \%)$.

Comparing voting patterns under different voting rules reveals that low frequencies of voting with the respective winning coalition are due mainly to opposition votes under the simple majority rule. Denmark, for example, voted in favor in only 17 of the 99 simple majority cases, and Sweden in 27 of these cases. The Netherlands voted yes in 69 of the 99 simple majority votes, in addition to voting in favor in only 207 of the 265 QMV cases. This QMV voting record is the second lowest, following Germany, whose government voted in favor of an adopted decision in 200 of the total of 265 cases.

Table 3 analyzes the extent to which winning coalitions that formed in the EU's Council corresponded to certain elementary aspects of coalition formation theories: were the coalitions formed minimal winning and does ideological connectedness on the left-right policy dimension matter? Although 197 of the winning coalitions (50\%) include the centrality area of the left-right dimension, we find that only 39 winning coalitions $(10 \%)$ were ideologically connected on the left-right policy scale. By comparison, there was no coalition that was minimal connected winning. We also find (albeit not shown in the table) that only 22 


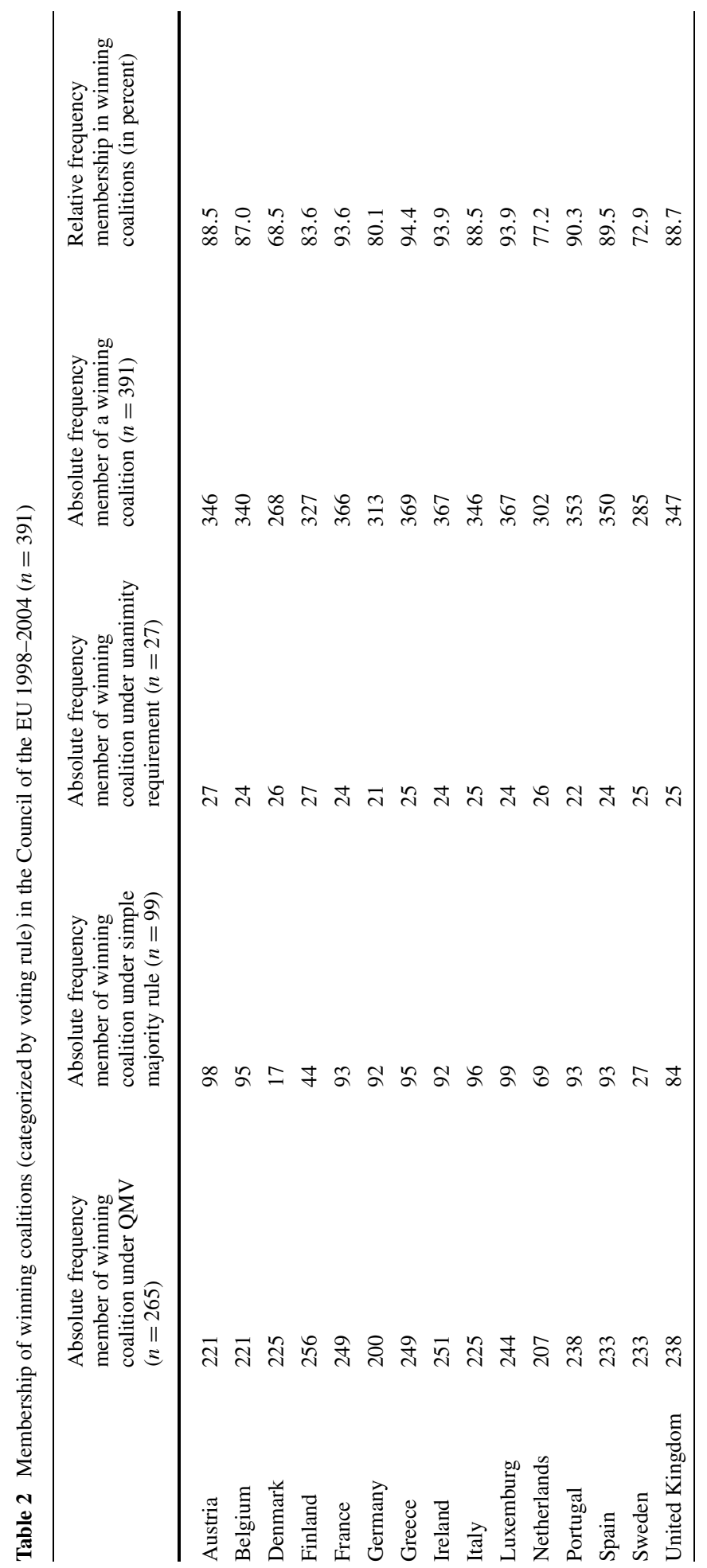


Table 3 Characteristics of winning coalitions in the Council of the European Union under different voting rules (based on coalition-theoretical approaches) 1998-2004

\begin{tabular}{|c|c|c|c|c|c|}
\hline \multirow{2}{*}{$\begin{array}{l}\text { Policy dimension } \\
\text { Voting rule }\end{array}$} & \multirow[t]{2}{*}{$\begin{array}{l}\text { Total number of } \\
\text { coalitions }\end{array}$} & \multicolumn{2}{|c|}{$\begin{array}{l}\text { Frequency of connected } \\
\text { winning coalitions }\end{array}$} & \multicolumn{2}{|c|}{$\begin{array}{l}\text { Frequency of winning } \\
\text { coalitions that include } \\
\text { the centrality area }\end{array}$} \\
\hline & & Left-right & Support EU & Left-right & Support EU \\
\hline Qualified majority & 265 & $30(11 \%)$ & $17(6 \%)$ & $109(41 \%)$ & $98(37 \%)$ \\
\hline Simple majority & 99 & $4(4 \%)$ & $3(3 \%)$ & $83(84 \%)$ & $73(74 \%)$ \\
\hline Unanimity & 27 & $5(19 \%)$ & $1(4 \%)$ & $5(19 \%)$ & $1(4 \%)$ \\
\hline Total & 391 & $39(10 \%)$ & $21(5 \%)$ & $197(50 \%)$ & $172(44 \%)$ \\
\hline
\end{tabular}

of the 391 coalitions were minimal winning, so the 'size only' approach does not provide a good fit.

Distinguishing between voting rules, the analysis reveals that of the 265 votes taken under the QMV rule, 109 (41\%) included the centrality area of the left-right policy dimension. Under the simple majority requirement, $84 \%$ of the votes contained the centrality area, compared to only $41 \%$ under QMV, and $19 \%$ under unanimity.

However, respective figures for winning coalitions based on the support for EU integration dimension are lower in all cases as compared to those based on the left-right policy scale: Out of all winning coalitions, only $5 \%$ were connected on this policy dimension, but 44\% do include the centrality area. Under the QMV rule, 37\% encompassed the centrality area, whereas $74 \%$ of the winning coalitions under the simple majority requirement included the central player of this policy dimension. By comparison, only four percent formed under the unanimity rule included the centrality area.

The second part of our empirical assessment is devoted to comparing the combined policy positions of the winning coalitions formed in the Council with the policy positions of the governments of individual EU states (one case).

The mean weighted left-right position of the winning coalitions formed in the EU's Council, for the 1998 to 2004 time span, is $0.51(N=391)$. The minimum (i.e., the most leftist weighted position) is 0.42 , and the maximum (i.e., the most rightist weighted position) is 0.58. Figure 2 shows how the mean weighted left-right and support for EU-integration positions of winning coalitions formed in the Council has developed between 1998 and 2004. The analysis reveals two distinct phases in mean left-right positioning: between 1998 and 2001, the EU's Council had a combined weighted policy position located somewhat to the left of the center, with values ranging from 0.42 to $0.47 .{ }^{22}$ By comparison, after 2001, the position of the Council clearly shifted to the right, with aggregate values on the left-right scale between 0.56 and 0.58 . By comparison, variations over time with respect to the support for EU integration dimension are relatively modest.

Table 4 shows for each policy dimension and each EU member state (1) the mean policy distance between the weighted left-right position of the member state's government and the one of the winning coalitions that formed in the Council, (2) the range of the policy distances on these dimensions between the respective coalitions and the member state and (3) the

\footnotetext{
${ }^{22}$ This confirms an observation by Hix (2008: 122-124) that since the end of the 1990 s, the "center of gravity" within the EU has shifted from the left to the right.
} 
Fig. 2 Mean weighted position of winning coalitions in the Council, 1998-2004

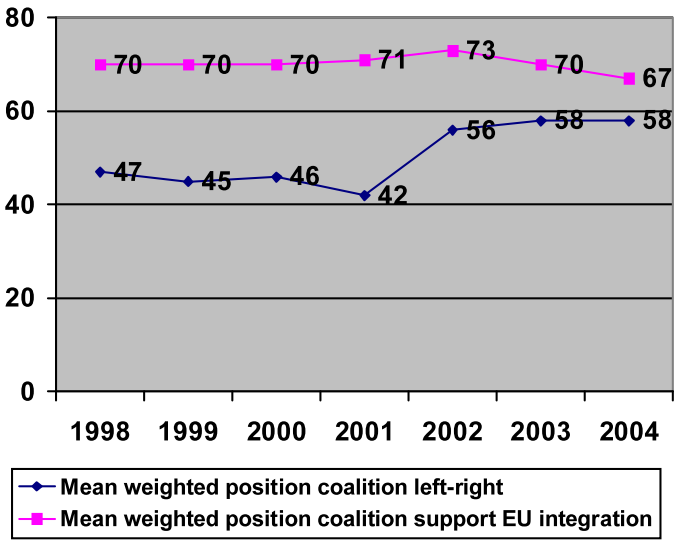

Pearson correlation coefficient between the weighted position of the winning coalition and the extent to which individual member states contributed to the weighted policy position of the coalition. ${ }^{23}$

The analysis of the policy distance of each member state to the weighted position of the winning coalition on the left-right policy dimension reveals a number of interesting results. For selected countries, the mean policy distance from the weighted position of the winning coalitions is small, with the outcome of the voting process in the EU's Council being close to their own preferred policy position (on the aggregate level of the respective policy scale). According to this assessment, five countries have a mean policy distance from the respective winning coalitions smaller than 0.10: the United Kingdom (0.03), Finland (0.05), The Netherlands (0.05), Belgium (0.07) and Portugal (0.07).

For most EU states, there is a clear connection between (1) the range associated with the mean policy distance, and (2) the policy distance between their own policy position and the weighted position of the winning coalition. This second measure shows the maximum policy distance member states were willing to accept in order to be a member of the respective winning coalition (again on the aggregate level of the policy scale). Strikingly, the five member states mentioned above are also the ones displaying the smallest range of policy distance, with the United Kingdom and Finland again being first and second in this respect. This small group of member states seems to be able to minimize the policy distance between their own position and the weighted policy position of the respective winning coalition. On the basis of this analysis, these member states could be seen as the 'winners' of the negotiation processes in the EU's Council in the 1998 to 2004 phase with regard to general disagreements based on the left-right policy dimension.

Similarly, using this strategy, it is fairly easy to point out the 'losers' in the Council's negotiation processes: Spain, Austria, Luxemburg and Sweden have a relatively high mean policy distance from the position of the winning coalitions, as well as a high range of policy distance as compared to other member states. Austria exhibits the widest range of all EU states, followed by Luxemburg, Greece, Ireland and France. This implies that Austria was the EU member most willing to stray away from its own policy position in order to be a member of the respective winning coalitions formed in the Council.

\footnotetext{
${ }^{23}$ We also computed correlations using the non-parametric Spearman's rho statistic (instead of Pearson's $r$ ). The results of both analyses were in most instances similar. For reasons of parsimony, we present only the Pearson correlations here.
} 


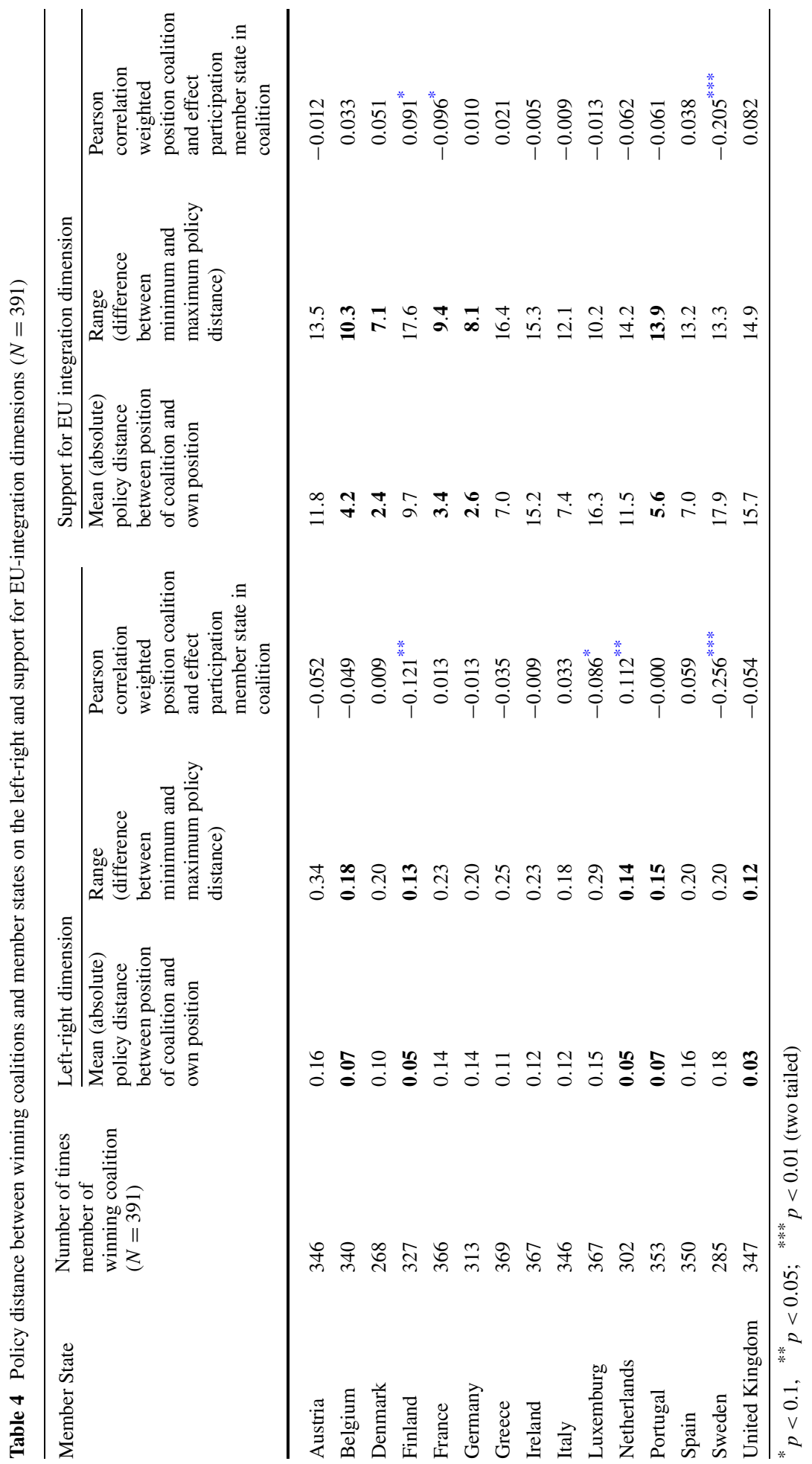


In regard to the dimension of support for EU integration, the countries with the smallest mean policy distance to the weighted position of the respective winning coalitions were Denmark (2.4) and Germany (2.6), followed closely by France (3.4) and Belgium (4.2). Analogously to the findings concerning the left-right dimension, Denmark, Germany and France are also the countries characterized by the smallest range of policy distance on this dimension. These states can hence be seen as 'winners' in the negotiation process on issues based on differences in the level of support for EU integration (the 'pro-/anti'-EU dimension).

By comparison, Sweden, Luxemburg, the United Kingdom and Ireland have a large mean policy distance from the weighted position of the winning coalition, as well as a relatively high range of mean policy distance on this dimension, constituting the 'losers' in this sense in the overall EU negotiation process.

The degree to which participation of member states in the winning coalition contributed to the weighted policy position of the coalition is captured by the Pearson correlations shown in Table 4. On the left-right policy dimension, this correlation is statistically significant only for four member states: Finland $(-0.121, p<0.05)$, Luxembourg $(-0.086, p<0.1)$, the Netherlands $(0.112, p<0.05)$ and Sweden $(-0.256, p<0.01)$. The participation of Finland and Sweden in the winning coalitions appears to have pulled the weighted position of the coalition to the left, whereas the inclusion of the Netherlands seems rather to have turned it to the right. ${ }^{24}$ On the support for EU integration dimension, the analysis reveals that the participation of Sweden in the coalition pulled the weighted position of this coalition to the left $(b=-0.205, p<0.01)$. Only a very weak correlation is found for Finland and France, with Finland pulling the position of the coalition on this dimension to the right, i.e., to a more Euroskeptic stance $(b=0.091, p<0.1)$, and France pulling it to the left, or to a more Europe-friendly position $(b=-0.096, p<0.1)$.

Figure 3 gives an illustration of the combination of the (mean) policy distances of all 15 EU member states on the two policy dimensions used in our analysis. Sweden and-to a somewhat lesser extent-Luxemburg and Austria are quite far from the combined policy positions of the winning coalitions on both policy dimensions. By comparison, Belgium and Portugal perform best on the combination of the two dimensions.

\section{Conclusion}

The aim of this paper was to provide an assessment of the types of winning coalitions that form within the EU's Council. With this, we also aim to contribute to the discussion about the dimensionality of political contestation in the EU. The approach we adopt focuses on the cooperative aspects of voting, notably in terms of the size and connectedness of winning coalitions. Our empirical exploration uses data on Council voting combined with information on the left-right and support for EU integration policy dimensions of member state governments between 1998 and 2004.

The results of our empirical analysis demonstrate that most winning coalitions formed in the EU Council display a relatively high combined voting weight. This implies that these

\footnotetext{
${ }^{24}$ In an exploratory multivariate regression analysis, the participation of the member states in winning coalitions were entered as independent variables to measure their effect on the weighted policy position of the winning coalition. With an R-squared of 0.14 , this analysis confirmed the effects for the Netherlands $(b=0.155$, $p<0.01)$ and for Sweden $(b=-0.370, p<0.01)$, as mentioned above. The result for Finland is not confirmed by this analysis, but results for Belgium $(b=-0.108, p<0.05)$ and Denmark $(b=0.207, p<0.01)$ do indicate significant effects.
} 


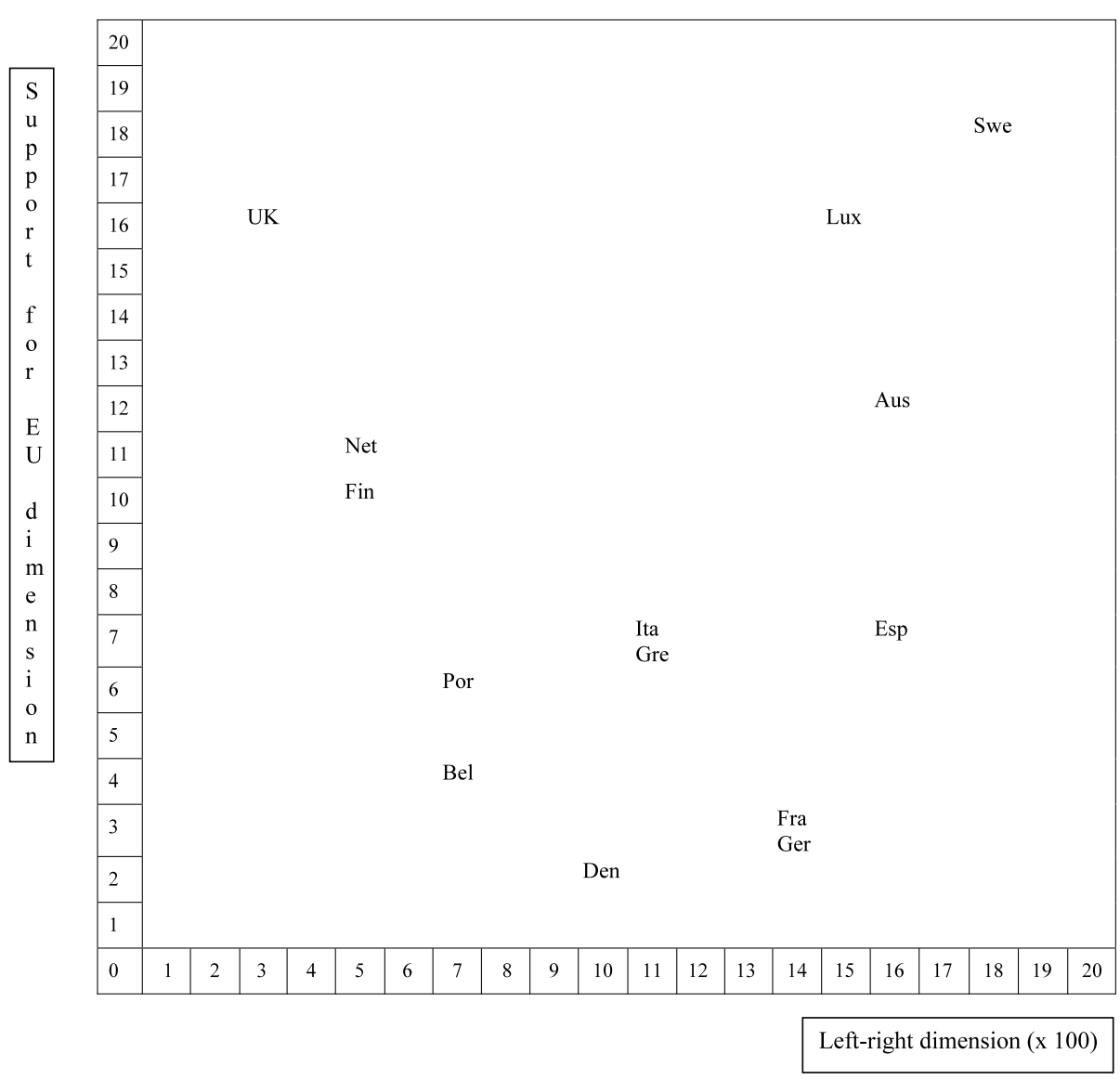

Fig. 3 Two-dimensional view of mean policy distance between the position of the coalition and the member states (1998-2004)

coalitions are clearly 'oversized'. However, about $25 \%$ of all winning coalitions have a much smaller combined voting weight, which is striking as the Council generally aims to achieve consensus.

The EU states that have most frequently been part of a winning coalition in Council voting procedures are Greece, Luxemburg, Ireland and France, whereas Denmark, Sweden and the Netherlands were included in winning coalitions less often. In the case of Denmark and Sweden, this is largely explained by their voting behavior in simple majority votes. For the Netherlands, it is due to vote choice in both simple majority and QMV voting procedures.

The results of our analysis also clearly indicate that minimal winning coalitions are a rare phenomenon in the Council. Moreover, contrary to general expectations, full ideological connectedness does not appear to be prevalent in winning coalitions in this institution. This also holds for the left-right policy scale. However, almost half of all winning coalitions on each policy dimension include the centrality area of that dimension (or, in the case of simple majority votes, the central player).

Finally, the analysis reveals that a fairly small group of EU states-most notably the United Kingdom, Finland, the Netherlands, Belgium and Portugal-have frequently partic- 
ipated in winning coalitions whose combined weighted policy position was relatively close to their own position on the left-right policy scale, implying that they were performing quite well on issues contested in the Council along this (aggregate) policy dimension. By comparison, on issues characterized by this dimension, Austria, Luxemburg, Greece, Ireland and France were generally less successful. It is interesting to note that among the member states, Greece, Luxemburg and Ireland most often participated in winning coalitions in the Council. Apparently, these states were willing to sacrifice the most policy congruence in order to be part of the respective winning coalitions.

On the-again somewhat aggregate-support for EU integration dimension, states performing quite well in the negotiations were Denmark, Germany, France and (again) Belgium. Those performing less convincingly on issues characterized by this dimension were Sweden, Luxemburg, the United Kingdom and Ireland. In the case of Luxemburg and Ireland, we detect the same pattern of high participation and low policy congruence that was discovered with respect to the left-right policy scale.

The analysis presented in this paper reveals some empirical insights on the nature of voting and coalition-formation in the Council and shows that it may be fruitful to assess EU decision-making on the basis of models different from purely single-dimensional conceptualizations of the EU policy space. ${ }^{25}$ In future research, it would be interesting to apply more complex theories of coalition-formation to the Council, to conduct multivariate assessments of links between policy positions and characteristics of winning coalitions and, finally, to distinguish between effects in different substantive areas of Council decision-making. In addition, in multivariate assessments, it might be fruitful to explore how other policy dimensions and other potential explanatory variables, such as GDP per capita or net budget positions of member states, affect the results presented herein.

Acknowledgements We notably thank Hannu Nurmi, Serguei Kaniovski, Abdul Noury, Mikko Mattila, Běla Plechanovová, Catherine de Vries and other participants of the 2008 workshop on 'Coalition-Formation in the European Union' (held at Leiden University, Netherlands) for helpful feedback on an earlier version of this paper. Financial support for the workshop by the project 'Efficient and Democratic Governance in a Multi-level Europe' (CONNEX) is gratefully acknowledged. In addition, research for this paper was facilitated by the Jean Monnet project 'Political Studies of the European Union', supported by the European Commission.

Open Access This article is distributed under the terms of the Creative Commons Attribution Noncommercial License which permits any noncommercial use, distribution, and reproduction in any medium, provided the original author(s) and source are credited.

\section{References}

Aspinwall, M. (2002). Preferring Europe. Ideology and national preferences on European integration. European Union Politics, 3(1), 81-111.

Austen-Smith, D., \& Banks, J. (1988). Elections, coalitions, and legislative outcomes. American Political Science Review, 82, 405-422.

Axelrod, R. (1970). Conflict of interest. Chicago: Markham.

Baron, D. P., \& Diermeier, D. (2001). Elections, governments, and parliaments in proportional representation systems. The Quarterly Journal of Economics, 116, 933-967.

Benoit, K., \& Laver, M. (2005). Party politics in modern democracies. London: Routledge.

\footnotetext{
${ }^{25}$ On the general importance of two-dimensional or multidimensional models in empirical assessments of decision-making in different political systems, see Schofield (2008).
} 
Boekhoorn, V., Van Deemen, A. M. A., \& Hosli, M. (2006). A cooperative approach to decision-making in the European Union. In R. Thomson et al. (Eds.), The European Union decides (pp. 178-210). Cambridge: Cambridge University Press.

Bueno de Mesquita, B., \& Stokman, F. N. (Eds.) (1994). European Community decision-making. Models, applications and comparisons. New Haven: Yale University Press.

Crombez, C. (1996). Legislative procedures in the European Community. British Journal of Political Science, 26, 199-228.

De Swaan, A. (1973). Coalition theories and cabinet formations. Amsterdam: Elsevier.

Felsenthal, D. S., \& Machover, M. (2001). The Treaty of Nice and qualified majority voting. Social Choice and Welfare, 18, 431-464.

Gabel, M., \& Hix, S. (2002). Defining the EU political space. An empirical study of the European elections manifestos, 1979-1999. Comparative Political Studies, 35(8), 934-964.

Garrett, G., \& Tsebelis, G. (2001). Understanding better the EU legislative process. European Union Politics, 2, 353-361.

Grofman, B., \& van Roozendaal, P. (1996). Modeling cabinet durability and termination. British Journal of Political Science, 27, 419-451.

Hagemann, S. (2005). Decision-making in the EU's Council of Ministers. Changes in voting behaviour across different stages of the legislative process. Mimeo.

Hagemann, S., \& Hoyland, B. (2008). Parties in the Council? Journal of European Public Policy, 15(8), 1205-1221.

Hayes-Renshaw, F., van Aken, W., \& Wallace, H. (2006). When and why the Council of Ministers of the EU votes explicitly. Journal of Common Market Studies, 44(1), 161-194.

Heisenberg, D. (2005). The institution of consensus in the European Union. Formal versus informal decisionmaking in the Council. European Journal of Political Research, 44, 65-90.

Hix, S. (2008). What's wrong with the European Union and how to fix it. Cambridge: Polity.

Hix, S. (1999a). The political system of the European Union. New York: St. Martins Press.

Hix, S. (1999b). Dimension and alignments in European Union politics: cognitive constraints and partisan responses. European Journal of Political Research, 35, 69-106.

Hix, S., \& Lord, C. (1997). Political parties in the European Union. Basingstoke: Macmillan.

Hix, S., Noury, A., \& Roland, G. (2007). Democratic politics in the European Parliament. Cambridge: Cambridge University Press.

Hooghe, L., Marks, G., \& Wilson, C. J. (2002). Does left-right structure party positions on European integration? Comparative Political Studies, 35(8), 965-989.

Hosli, M. O. (1996). Coalitions and power. Effects of qualified majority voting in the Council of the European Union. Journal of Common Market Studies, 34(2), 255-273.

Hosli, M. O. (2007). Explaining voting behavior in the Council of the European Union. Paper presented at the 1st World Meetings of the Public Choice Societies, Amsterdam, March 29-April 1.

Hosli, M. O., \& Van Deemen, A. M. A. (2002). Effects of enlargement on efficiency and coalition formation in the Council of the European Union. In M. O. Hosli, A. M. A. Van Deemen, \& M. Widgrén (Eds.), Institutional challenges in the European Union (pp. 65-88). London/New York: Routledge.

Hosli, M. O., \& Machover, M. (2004). The Nice Treaty and voting rules in the Council: a reply to Moberg (2002). Journal of Common Market Studies, 42(3), 497-521.

Hosli, M., Mattila, M., \& Uriot, M. (2011, forthcoming). Voting in the Council of the European Union after the 2004 enlargement. Journal of Common Market Studies.

Laver, M., \& Hunt, W. B. (1992). Policy and party competition. London: Routledge.

Laver, M., \& Shepsle, K. A. (1996). Making and breaking governments. Cabinets and legislatures in parliamentary democracies. Cambridge: Cambridge University Press.

Laver, M., \& Schofield, N. (1990). Multiparty government. The politics of coalition in Europe. Oxford: Oxford University Press.

Leech, D. (2002). Designing the voting system for the Council of the European Union. Public Choice, 113(3-4), 437-464.

Luce, R. D., \& Raiffa, H. (1957). Games and decisions. Introduction and crucial survey. New York: Wiley.

Marks, G., \& Steenbergen, M. (2004). Marks/Steenbergen party dataset. Chapel Hill: University of North Carolina Press. Available at http://www.unc.edu/ gwmarks/data.htm.

Mattila, M., \& Lane, J.-E. (2001). Why unanimity in the Council? A roll call analysis of Council voting. European Union Politics, 2(1), 31-52.

Mattila, M. (2004). Contested decisions: empirical analysis of voting in the European Union Council of Ministers. European Journal of Political Research, 43(1), 29-50.

Nurmi, H., \& Meskanen, T. (1999). A priori power measures and the institutions of the European Union. European Journal of Political Research, 35, 161-179. 
Plechanovová, B. (2011). The EU Council enlarged. North-south-east or core-periphery? European Union Politics, 12(1), 87-106.

Rapoport, A. (1970). N-person game theory. Concepts and applications. Ann Arbor: University of Michigan Press.

Riker, W. H. (1962). The theory of political coalitions. New Haven/London: Yale University Press.

Riker, W. H. \& Ordeshook, P. C. (1973). Introduction to positive political theory. Englewood Cliffs: Prentice Hall.

Schneider, C. J. (2007). Enlargement processes and distributional conflicts. The politics of discriminatory membership in the European Union. Public Choice, 132(1-2), 85-102.

Schofield, N. (2008). The spatial model of politics. New York: Routledge.

Sened, I. (1995). Equilibria in weighted voting games with side payments. Journal of Theoretical Politics, 7 , 283-300.

Shapley, L. (1962). Simple games. An outline of the descriptive theory. Behavioral Sciences, 7, 59-66.

Shapley, L. S., \& Shubik, M. (1954). A method for evaluating the distribution of power in a committee system. American Political Science Review, 48(3), 787-792.

Sherrington, P. (2000). The Council of Ministers: political authority in the European Union. London/New York: Pinter.

Steunenberg, B. (1994). Decision-making under different institutional arrangements: legislation by the European Community. Journal of Theoretical and Institutional Economics, 150, 642-669.

Steunenberg, B., Schmidtchen, D., \& Koboldt, C. (1999). Strategic power in the European Union: evaluating the distribution of power in policy games. Journal of Theoretical Politics, 11, 339-366.

Thomson, R., Stokman, F., Achen, C. H., \& König, T. (Eds.) (2006). The European Union decides. Cambridge: Cambridge University Press.

Tullock, G. (1976). The vote motive. Lansing: Institute of Economic Affairs.

Van Deemen, A. M. A. (1987). Dominant players, central players and coalition formation in simple games. Paper presented at ECPR joint sessions of workshops, April 10-15.

Van Deemen, A. M. A. (1989). Dominant players and minimum size coalitions. European Journal of Political Research, 17, 313-332.

Van Deemen, A. M. A. (1997). Coalition formation and social choice. Boston/Dordrecht: Kluwer.

Van Roozendaal, P. (1992a). The effect of dominant and central parties on cabinet composition and durability. Legislative Studies Quarterly, 17, 5-36.

Van Roozendaal, P. (1992b). Cabinets in multi-party democracies: the effect of dominant and central parties on cabinet composition and durability. Amsterdam: Thesis Publishers

Van Roozendaal, P. (1994). Coalition predictions with ordinal policy position data. British Journal of Political Science, 24(1), 132-138.

Von Neumann, J., \& Morgenstern, O. (1947). Theory of games and economic behavior. Princeton: Princeton University Press.

Widgrén, M. (1994). Voting power in EC decision-making and the consequences of two different enlargements. European Economic Review, 38, 1153-1170. 